\title{
Challenges and Strategies of Abidjan Port-Hinterland Connectivity
}

\author{
Pascal Kany Prud'ome Gamassa ${ }^{1}$ and Yan Chen $^{2}$ \\ ${ }^{1-2}$ Dalian Maritime University, Transportation and Management College, No. 1 Linghai Road, 116026, Dalian, China
}

\begin{abstract}
Abidjan port-hinterland is composed of three countries which include Ivory Coast, Mali and Burkina Faso. The fast economic growth of the above countries resulted to a greater demand for the foreign goods from their population, causing a congestion problem at Abidjan port. Because of this problem, the connectivity movement between the port and its hinterland has considerably slowed down. In this article a qualitative methodology is used to analyse the Abidjan port-hinterland connectivity. The constant delays of the train services, the road congestion and the lack of coordination and communication between Abidjan port and its hinterland customers are the main presented challenges. The results of this research demonstrate that the poor quality roads and railways and the lack of a new dry port in Ivory Coast greatly affects the fluidity of the Abidjan port-hinterland connectivity. This article suggests some strategies on how to solve the current challenges and will be helpful in deciding on how the Abidjan port should be developed better and improve its connectivity with its hinterland.
\end{abstract}

\section{Introduction}

Nowadays, every major port of West Africa aims to develop and expand its hinterland, thus there is a high level of competition among the ports in this region. Abidjan port is a port which looks forward to becoming the hub port of the entire west coast of Africa. To reach this objective it is important to maintain the current customers of the port and also attract new customers and investors. Indeed, the more customers the Abidjan port can get, the more revenue it can obtain. As regard to maintaining its position of a leading port in the region, it is important to facilitate the accessibility of the Abidjan port to its hinterland. Port is the foundation industries of the national economy and critical infrastructure of transport system [1]. The hinterland of a port is basically made up of areas where the port serves and can be served from [2]. Despite the fact that in West Africa, customers of the hinterland pay greater attention to the distance between their current location to the nearest ports and the facilities, the rates and the services proposed by these ports, but nowadays their connectivity to the chosen port is one of the first priority they think about in making their final decision. Analysing Abidjan port-hinterland connectivity is of great importance for the Abidjan port Authorities as it will help to develop a better plan for the development of Abidjan port. Construction and development of ports logistics can support the regional and even the country's economy [3]. In this article, a qualitative methodology is applied and face to face interviews were conducted with representatives of Abidjan port Authorities, some regular customers of Abidjan port, some officials of the Sitarail Company that is in charge of linking Abidjan port to its hinterland by railway, some representatives of private companies operating in Abidjan port, some officials of Ivory Coast's customs administration, some representatives of the Ivorian Shippers' Office, the Burkinabe shippers' Council, the Malian shippers' council and other stakeholders. The data being used were collected from the official websites of the World Bank database, the distance calculator and the interviews. This research aims at analysing the challenges currently faced by the Abidjan port-hinterland connectivity and providing some solutions to those problems.

\section{Literature review}

The transportation system between a port and its hinterland plays an important role in their connectivity. The port and the hinterland bear a relationship of facilitating and conditioning each other [4]. Because of the current high competition among ports of the same regions in the world, topics related to port-hinterland supply chain management and connectivity, are of great interests for many researchers. Researchers who have already written papers on similar topics have in majority noted that multimodal transport should be developed and a port and its hinterland can never be dissociated, thus thinking about developing a port automatically means developing the port connectivity with its hinterland. They wrote about different aspects of port-hinterland connectivity. This article is the first to present a complete analysis of the current challenges in the overall Abidjan port-hinterland corridor connectivity, using two routes, Abidjan-Bamako route and Abidjan-Ouagadougou route, and to provide concrete solutions to this particular case. 
M. Zhang, B. Wiegmans and L. A. Tavasszy presented up to date insights of intermodal transport development in port of Shanghai, port of Rotterdam and their hinterlands via a comparative study. Their paper introduced the recently completed or underway projects carried out in both of the hinterland transport systems. They concluded that at this moment, construction of rail facilities near the Shanghai port is not effective, because the capacity for container transport in the national rail network is very limited and the newly launched sea port container terminals cause increased congestion on motorways as a result of the providing more handling capacity of the sea side. The different projects helped to improve the accessibility of the port of Rotterdam, but still further improvements are needed as especially road transport access of the port of Rotterdam is limited, difficult to extend, and vulnerable for accidents [5]. Davide Infante, Giuseppe Paletta and Francesca Vocaturo in their article focused on an intermodal freight transport service in which containers represent the moved loading units. With a view to minimizing the total cost of the service, they formulated a ship-truck intermodal transportation problem as a Travelling Purchaser Problem (TPP), in this way broadening the real-world applications field of the TPP. To tackle this problem, a heuristic algorithm was presented and experimentally tested. Computational results indicated that the algorithm was very efficient on a set of benchmark instances, quickly achieving optimal or near-optimal solutions [6]. On the basis of analyzing customer's choice behavior, Nannan $\mathrm{Hu}$, Jie Wang and Dong $\mathrm{Mu}$ in their paper constructed a utility function of port and obtained an equilibrium pricing strategy before and after competition and cooperation by applying Nash equilibrium. They also analyzed the impact of hinterland traffic condition on the competition and cooperation between ports. The analyzed results demonstrated that with the improvement of hinterland traffic condition, part of ports use cooperation strategy, which can not only improve the overall profit and share of the cooperative ports, but also can enhance the interest and market share of non-competitive ports so that the improvement of overall interest and market share of regional port group can be realized [7]. ShuHai Zhao, Wei Liang and Dan Han in their paper put forward a logistics information sharing platform framework facing e-commerce for an international Seaport of China abbreviated QDIP. They think that the platform changed all aspects of port services information passive situation, and not only improved the customs clearance and regional logistics operation efficiency and reduce logistics costs and increase trade opportunities, but also contributed greatly to the improvement of port business environment. Through the platform, enterprises can reduce intermediate links and costs and obtain economic benefits from goods circulation and cash flow [8]. Benyi Xie, Huiyuan Jiang, Jin Zha and Xiang Li in their article established a Logistic exponential regression model, applied marginal analysis and elastic analysis to analyze the interaction effects between Wuhan port and its hinterland's economy. They proposed that the construction of Wuhan Yangtze should be enhanced to better serve for regional economy development and guarantee the middle boost strategy. Their findings showed that the marginal effect of Wuhan port cargo handling capacity on Wuhan GDP increases every year [9]. Fedele Iannone's article presented an optimization model for the economic analysis and strategic planning of port-hinterland container logistics systems. The model was employed to investigate the inland multimodal distribution of import/export containers handled at the seaports located in the Campania region of Southern Italy. A numerical prototype was formulated and solved using a high-level programming language for large-scale mathematical optimization problems. The results found demonstrated how the competitiveness of the regional container seaport cluster can be boosted by an inter-port based extended gateway system with adequate customs facilities and improved railway connections [10]. Charles Kipkoech Kotut and Dr. Fred Mwirigi Mugambi in their paper focused into the influence of hinterland logistics and transport connectivity on the port of Mombasa with the objective of determining the northern corridor inefficiencies and how they influence performance of port of Mombasa. They employed a descriptive research to describe the state of affairs as it exists and a stratified sampling method to reach at most representative respondents in the study universe of fifty-eight respondents covering port users and clearing and forwarding agents, port officials and leading transport and logistics organizations: KSC and KMA. Questionnaires and interviews were used by the researchers as instruments to collect data and finally analyze and synthesize for presentation using Microsoft Excel data analysis software for purposes of achieving objectives. The findings of the research effectively revealed that the influence of hinterland transport inefficiencies on performance by Kenyan Ports Authorities was glaring. Northern corridor inefficiencies was found to contribute to slow uptake of cargo into the hinterland leading to high truck turn round time and therefore high cargo dwell time at the port, leading to a conclusion that indeed hinterland transport connectivity plays a significant role in the success of ports [11]. Elvira Haezendoncka, Michael Doomsa and Alain Verbeke developed a new governance perspective on porthinterland linkages and related port impacts, by using a governance lens to assess this farsighted contracting challenge. They used the PHI matrix in their empirical, governance-based analysis of contractual relationships between the port authorities in Antwerp and Zeebrugge, and their respective stakeholders. Their findings revealed that the used matrix represents a critical complement of traditional value added and employment-related impact analyses, which are typically restricted to a narrow geographic zone and are devoid of insight into the nature of contractual relationships with actors located outside of the port and immediately adjacent geographic areas [12].

However, An Caris, Cathy Macharis and Gerrit K. Janssens in their paper, developed a service network design model for intermodal barge transport which was applied to the hinterland network of the port of Antwerp in Belgium. Selected cooperation schemes were simulated by means of a discrete event simulation model for intermodal barge transport and compared with 
simulation results of bundling in the port area. They concluded that cooperation between inland terminals offers an opportunity to attain economies of scale, but may not be perceived as a sole solution for reducing waiting times of inland barges at sea terminals. Thus a combination of bundling measures in the port area and in the hinterland may be necessary to improve the intermodal transport chain [13]. In his article, Dr. Olivier Podevins highlighted the decisive role of terminals in the hinterland and the changing structure of the terminal network in Western and Central and Eastern Europe (CEE) based on the empirical evidence and market observations. In this concern he firstly considered the main seaports of the Northern Range and their connected terminal network system in Western Europe, as well as the development on the Mediterranean/Black Sea Range and the terminal network in Central/Eastern Europe. He mentioned in his findings that strategic partnerships between seaports and in land waterways ports such as Duisburg, and the ARA-Ports or between Constanta and Vienna has to be seen as a long term process in order to reduce port congestion and increase scales. And he added that intermodal terminals located on existing transport corridors by rail, road and inland navigation between the heart of the EU, the Mediterranean, East and Central Europe provide important new impulses for strategies in an enlarged European Union [14]. Ying Wang and Jian Wang after having studied the regional economy and transportation situation of the western side of the Taiwan straits port group, firstly set up an evaluation index including factors that influence the dry port, secondly used Fuzzy Cluster Analysis to select and rank the candidate locations, and finally classified three grades of locations, each requiring a different construction strategy. Their findings revealed that from the view of geological location and promotion of regional economy, Longyan, Sanming, and Nanping cities should be considered as first grade locations to build dry port, and the cities of Changsha and Nanchang should be considered as second grade locations, while the other cities should be considered as last grade locations [15].

\section{Overview of Abidjan port and its hinterland}

Inaugurated in 1951, Abidjan port is the major port of Ivory Coast. It has access to the Atlantic Ocean through the Vridi canal and also plays a great role in the economic development of the country. It serves as a gateway for Mali and Burkina Faso. The Abidjan port hinterland is thus considered to have a total population of about 52.28 million people and a surface area of about $1,836,872$ square kilometres. Ivory Coast has cobalt, nickel, copper, iron, diamonds and natural gas as main mineral resources. Mali has salt, phosphates, uranium and gold as the main natural resources. Burkina Faso has manganese, gold, marble as the main mineral resources and its economy greatly relies on the agricultural production. Because mineral resources are great source of revenue for these countries, therefore it is important for their authorities that these resources can be easily exported. On the other hand, the large profits made by these countries from selling their natural resources have contributed to the improvement of the living conditions of their population. This resulted into a net growth of these countries' Gross Domestic Product which has created a demand problem. Because of the higher consumption power, population of these regions consumes more imported goods. Most of these goods transit through Abidjan port. The Table 1 illustrates the Abidjan container throughput from the year 2007 to the year 2014. It is important to note that by the time this paper was written, the Abidjan port container throughput of the year 2014 was the latest data available in the World Bank database [16].

Table 1. Abidjan port container throughput annual, 2007-2014; Measure: TEU (Twenty-foot Equivalent Unit); Source: World Bank data 2015.

\begin{tabular}{|c|c|}
\hline Years & $\begin{array}{c}\text { Abidjan Port } \\
\text { Container } \\
\text { Throughput }\end{array}$ \\
\hline 2007 & 590,306 \\
\hline 2008 & 713,625 \\
\hline 2009 & 677,029 \\
\hline 2010 & 607,730 \\
\hline 2011 & 642,371 \\
\hline 2012 & 690,548 \\
\hline 2013 & 745,102 \\
\hline 2014 & 783,102 \\
\hline
\end{tabular}

The Abidjan port is expected to reach 15,952,521 TEUs by 2020 [17]. From Table 1 it can be seen that the container throughput of Abidjan port kept increasing from 2007 to 2009 . Due to the political crisis that Ivory Coast went through in 2010, its container throughput decreased in that year but restarted to increase after the crisis in 2011. Since then a constant growth has been noticed. It is important to mention than since the year 2011, Ivory Coast became the second economic power in West Africa after Nigeria which is the first, and the Abidjan port authorities hope to attract more customers, investors and ships in the coming years. Mali and Burkina Faso economies positively grew notably due to the increase of the selling prices of the mineral resources that these countries export. For the year 2017, Ivory Coast's doing business rank is 142, Mali's is 141 while Burkina Faso's is 146 over 190 countries all over the world [18]. Their ranking positions are among the best in the West African region. These data show that these countries are normally attractive for potential investors.

\section{Abidjan port-hinterland connectivity challenges}

The connectivity between Abidjan port and its hinterland is mainly done by railways and roads. This was facilitated 
by the fact that the three countries belong to the Economic Community of West African States (ECOWAS) which guarantees citizens of this region to freely move their goods from one country to another. The different challenges of Abidjan port-hinterland connectivity are thus introduced in two routes, Abidjan-Ouagadougou route and Abidjan-Bamako route. It is difficult to underestimate the transportation disadvantages that landlocked countries face in international trade logistics and transportation [19]. In Africa, the efficiency of the transport chain and of the maritime services is hampered by poor connectivity to markets, resulting from the poor quality and high cost of land transport infrastructure [20]. The Fig. 1 below represents the railway from Abidjan in Ivory Coast to Ouagadougou which is the capital city of Burkina Faso. In Fig. 1, the red colour line represents the existing railway while the green colour line represents the railway that is about to be built. As it can be noticed, there is a total absence of railway from Ivory Coast to Mali. Consumers thus use two logistics methods: they can firstly transport their goods from Abidjan directly to Bamako, which is the capital city of Mali, by road or secondly transport them from Abidjan to Bouake by train and then from Bouake to Bamako by road.

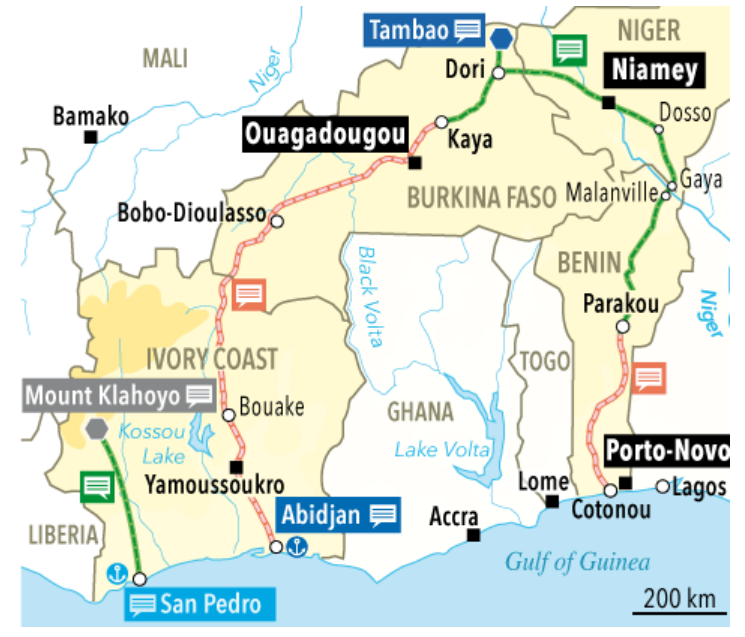

Figure 1. Railway from Abidjan to Burkina Faso

The distance from Abidjan to Ouagadougou is 830 kilometres and the distance from Abidjan to Bamako is 926 kilometres [21]. It takes 5 days for a truck to go from Abidjan to Ouagadougou [22]. There are about 40 checkpoints along the route from Ouagadougou to Abidjan. This is not normal because at each check point a truck driver has to pay a certain amount of money to pass, thus this is a sign of bribery. Every stop at checkpoints creates a delay. In Ivory Coast, while the truck drivers are driving from the hinterland to Abidjan port, they can also be stopped at any moment by the local police for their trucks' papers to be checked. They also mostly have to give the policemen a certain amount of money as bribery to continue their trip without any problem. These briberies directly result in the increase of the final price of the goods that are sold on the hinterland markets, making it expensive for hinterland local buyers. There is a railway line of 1,260 kilometres between Abidjan and Bamako [23]. This line was partly damaged at the beginning of this century when Ivory Coast had a sociopolitical crisis and after the presidential elections in 2010. There is a train service from Abidjan to Ouagadougou three times per week, taking thirty-six hours to arrive at destination. Unfortunately, these train services have mostly delays of several hours, which is not very convenient.

Hinterland customers do not usually receive any update on whether there are new regulations at Abidjan port especially which concern the rates and the documents to present for importing or exporting goods. There is constant road congestion on the road leading to Abidjan port in Abidjan and on the roads to Bamako and Ouagadougou. This is so inconveniencing and it is mainly due to the poor quality roads, the lack of interchange roads, and the small size of roads. Accidents are nowadays also noticed a lot on these roads. Moreover, Abidjan port does not communicate with its hinterland customers, which is something inacceptable. Though Ivory Coast has become a political stable country, but truck drivers also face armed robberies problem on these roads. These are done by ex rebels, who still have guns and whose main business has become to steal goods and money from trucks drivers. Nowadays, almost once in a month Ivory Coast's soldiers launch mutinies demanding higher salaries to the government and when doing that, they put stop barriers on all the roads heading to Abidjan, preventing any cars including truck drivers from reaching Abidjan [24]. This causes delays. Areas around ports are usually congested and worst of all they have pitiable road infrastructures [25]. Once they arrive at the Abidjan port main entrance gate, truck drivers usually park on the two sides of the road, which creates a terrible traffic jam in that zone. They usually park this way to wait for the loading or the unloading of the goods because there is no parking reserved for them. Trucks are mostly overloaded which not only affects the conditions of the vehicles but can also create accidents. It even happens that some drivers of trucks run away with the goods that they were supposed to deliver to a customer of the Abidjan port who is from the hinterland. The Abidjan port Authorities seem not to pay much attention to the hinterland logistics management as it mostly happens out of the Abidjan port.

\section{Suggested strategies}

Based on the findings of this article, for the first time some strategies on how to solve the challenges mentioned above are suggested. These strategies can be easily implemented with the great will of the Ivory Coast's government, Abidjan port Authorities and their different partners.

\subsection{Build a new dry port in Ivory Coast}

After analysing the Abidjan port-hinterland connectivity current situation, building a new dry port in Korhogo is found as a good solution. It will not only help to solve the road congestion problem and to decongest Abidjan port but also to promote the city, develop the city, create more jobs for locals and attract potential investors. The revenue 
generated by this new dry port can contribute to improve the quality of life of the local citizens by building hospitals, schools, etc. In the Fig. 2 below, which was adapted by the authors from Wordtravels, the city of Korhogo is indicated with a black arrow. As it can be seen, it is really close to Mali and Burkina Faso [26].

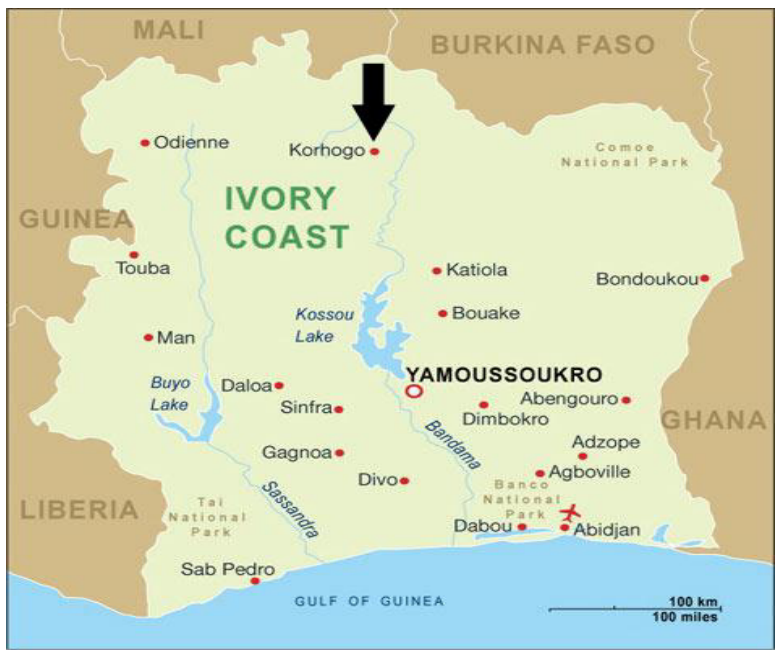

Figure 2. Korhogo new dry port location

The choice of Korhogo can be explained by the fact that it is the most populated city in the northern part of Ivory Coast and the distance to Bamako is 439 kilometres, to Ougadougou is 552 kilometres and to Abidjan is 495 kilometres. To give the customers from the hinterland a fast access to this new dry port, two highways can be built, one linking Bamako directly to Korhogo and the other linking Ouagadougou to Korhogo. This is a cost effective strategy. Based on the data of the population number and the GDP of the countries of Abidjan porthinterland which show a constant growth since the beginning of this new century, it can be said that this strategy will serve on a long run basis.

\subsection{Set up a communication platform}

A communication platform needs to be set up for Abidjan port to exchange information with customers and trucks drivers. It can be created on an online platform through a website or in a physical platform through the establishment of an information centre which will facilitate communication to the customers of the different information related to the port while noting down their different request and complaints.

\subsection{Open up a new department in charge of hinterland connectivity at Abidjan port}

A department in charge of Abidjan port-hinterland needs to be opened, as people working in this department will be fully in charge of the connectivity route of the port to its neighbouring countries. This department will work in partnership with Mali's and Burkina Faso's Infrastructure Bureau, the Sitarail Company, the Ivorian Shippers' Office and the customs administrations of the three countries located in Abidjan port hinterland.

\subsection{Build a new railway}

If a railway which will link Abidjan directly to Bamako is not built, the Abidjan port will lose this part of its hinterland to Dakar port in Senegal whose government is currently renovating the direct railway to Mali with the help of the Chinese government. Ivory Coast and Mali governments can ask private investors or other foreign governments' help, to fund this project, like other countries do. An agreement can be made among the different parties, but the two countries in the long run will be the great beneficiaries of this investment as the railway will be built in their country, which will boost their countries' economies and attract more potential investors.

\subsection{Renovate the existing railway and regulate train services time}

Many customers in West Africa usually prefer to transport goods by train instead of using trucks as it is faster and cheaper. It helps to avoid the numerous checking points that the roads have. It is thus important to regulate the train services time so that train can always leave on time. It will help the customers to save time and will also boost the traffic hence creating higher profits.

\subsection{Build new roads connecting Abidjan to Abidjan port-hinterland}

With the help of potential partners, new roads that respect international standards can be built. These roads will link Abidjan port directly to Bamako and Ouagadougou. The current roads are of poor quality and very small. To accelerate the delivery time of goods from the port to its hinterland, having large roads will enable drivers to avoid losing time in traffic jam as it can be seen currently.

\subsection{Create a special parking and management system for trucks}

Trucks that arrive at Abidjan port should be better managed by creating a system that can manage them. A special parking can be built for them to avoid the traffic jam at the entrance of Abidjan port. Trucks drivers should be able before arriving at Abidjan port, to check online the status of the goods they will collect, to know approximately at what time they should arrive at the port. This will help hinterland truck drivers to save time, by reducing their time spent in Abidjan. By being faster they can be able to make more turns and earn more money.

\subsection{Reduce checkpoints on the roads}

Based on the regulations of ECOWAS, the importance of having many checking points on the Abidjan porthinterland route is not justified. Thus, reducing the number of checkpoints to two checkpoints will drastically reduce the checking fees paid by the truck drivers. The amount of the checking fees should also be lowered down 
in order to attract more customers. The strategy will be to reduce prices and have a lot of customers instead of having higher prices but just few customers.

\subsection{Reinforce security in the corridor}

Security on the Abidjan-Bamako-Ouagadougou corridor should be reinforced by Ivory Coast authorities as it is a very strategic corridor for Ivory Coast's economy. A part of the large profits made by the authorities in the taxes paid by the truck drivers can be used to pay very well police officers that will be ensuring security along the corridor.

\subsection{Exchange information among Custom services}

Information and data should be exchanged between Abidjan port customs and customs services of its hinterland in order to have a better control of the goods that are exported from or imported goods in the hinterland. This will contribute to harmonise the decisions of each country governments on what are the kind of goods that can be imported in the Abidjan porthinterland area or exported from this area. The customs administrations and the local police authorities of the three concerned countries can work together in seriously punishing overloaded trucks. As an example the drivers of those trucks can be asked to pay a very high amount of money as a fine.

\subsection{Set up a tracking system for trucks}

A tracking system should be set up by shippers' council of each of the three concerned countries in partnership with local authorities and Abidjan port Authorities in order to identify the different trucks drivers operating in the Abidjan-Bamako-Ouagadougou corridor, their trucks conditions and quality, and if necessary give the information on a truck to local hinterland customer. This will help the countries authorities to have some control on the trucks drivers operating in the region. They will be able to easily locate a truck and in case of complaints from customers, to easily find the driver of a truck.

\section{Conclusion}

Abidjan port that has the largest hinterland in West Africa was presented in this article and its connectivity system with its hinterland reviewed and assessed. It has been noted that without the establishment of a department in charge of managing, coordinating the hinterland connectivity at Abidjan port and the construction of a dry port, it will be difficult to offer an efficient service to customers. The governments of the countries located in the hinterland should also greatly contribute to the improvement of the port-hinterland connectivity by building new roads and railways with the help of some private investors or some foreign governments or institutions. As Ivory Coast aims to become an emerging country by 2020, tackling the current challenges mentioned above by using the proposed strategies that embody the two routes, Abidjan-Bamako and AbidjanOuagadougou, can be beneficial to the country and to the West African region in general. This article reveals that a great collaboration between the different entities composing the Abidjan port hinterland will contribute to the improvement of the Abidjan port-hinterland connectivity. An important insight is given on how having an excellent connectivity between the port and its hinterland can not only attract a lot of potential partners, investors and customers but also generate higher revenue to the Abidjan port. If the proposed recommendations are not applied there is a great risk that Abidjan port loses its hinterland market to Tema port in Ghana and Dakar port in Senegal in the coming years. This article can serve as a reference for future researchers, Abidjan port Authorities, maritime experts and all the institutions and companies that are involved in the Abidjan port-hinterland connectivity.

\section{Acknowledgment}

This work was supported by the National Natural Science Foundation of China (Grant No. 71271034), the National Social Science Foundation of China (Grant No.15CGL031) and the Fundamental Research Funds for the Central Universities (Grant No. 3132016306 and 3132017085).

\section{References}

1. Wang Jie, Zhang Huaqiang, “Analysis on hinterland segmentation in port project", International Conference on Engineering Computation, pp. 84-88 (2009)

2. Tetteh Evans, Hualong Yang, "Hinterland Demarcation Between Two West African Ports", International Conference on "Multidisciplinary Academic Research and Global Innovation", (2015)

3. Wang Yang, Huang Wenwen, "Economic Analysis of Logistics Financial Management of Supply Chain System in Ports-Hinterland", International Conference on Electronic Commerce and Business Intelligence, pp. 207-212, (2009)

4. Wang Yang, Ma Xing-rui, Chen Yuan-zhi, "Study on the Harmonious Operation of Logistics Finance Management of Supply Chain in Ports-Hinterland Based on System Dynamics", International Conference on Risk Management and Engineering Management, pp. 82-86, (2008)

5. M. Zhang, B. Wiegmans, L. A. Tavasszy, "A Comparative Study on Port Hinterland Intermodal Container Transport: Shanghai and Rotterdam”, The Fifth Advanced Forum on Transportation of China, pp. 15-25, (2009)

6. Davide Infante, Giuseppe Paletta and Francesca Vocaturo, "A ship-truck intermodal transportation problem", Maritime Economics and Logistics, vol. 11, no. 3, pp. 247-259 (2009)

7. Nannan Hu, Jie Wang, Dong Mu, "Research on the Cooperation and Competition Strategies of Port 
Based on Hinterland Traffic Condition", International Conference on Logistics, Informatics and Service Sciences, (2016)

8. ShuHai Zhao, Wei Liang, Dan Han, "Seaport Logistics Information Sharing Platform in Ecommerce: A Case Study of QDIP in China", Asian Himalayas International Conference on Internet, $\mathrm{pp}$. $1-4,(2012)$

9. Benyi Xie, Huiyuan Jiang, Jin Zha, Xiang Li, "Analysis of interactive effect between the port and the hinterland based on logistic model", Third International Conference on Intelligent System Design and Engineering Applications, pp. 304-307, (2013)

10. Fedele Iannone, "A model optimizing the porthinterland logistics of containers: The case of the Campania region in Southern Italy", Maritime Economics and Logistics, vol. 14, no. 1, pp. 33-72, (2012)

11. Charles Kipkoech Kotut, Dr. Fred Mwirigi Mugambi, "The Influence of Hinterland Transport Inefficiencies on the Performance of Ports-A Case Study of Kenya Ports Authority", International Journal of Science and Research, Vol. 3, no. 8, pp. 405- 417, (2014)

12. Elvira Haezendonck, Michael Doomsa, Alain Verbeke, "A new governance perspective on porthinterland relationships: The Port Hinterland Impact (PHI) matrix", Maritime Economics and Logistics, vol. 16, no. 3, pp. 229-249, (2014)

13. An Caris, Cathy Macharis, Gerrit K. Janssens, "Corridor network design in hinterland transportation systems", Flexible Services and Manufacturing Journal, vol. 24, no. 3, pp. 294-319, (2012)

14. Dr. Olivier Podevins, "Sea Port system and the inland terminals network in the enlarged European Union", International Symposium on Logistics and Industrial Informatics, pp. 151-155, (2007)

15. Ying Wang, Jian Wang, "The Optimal Location of Dry Port: A Case Study of the Hinterland of Western
Side of the Taiwan Straits Port Group", International Conference on Industrial Engineering and Engineering Management, pp. 1864-1868, (2010)

16. http://data.worldbank.org/indicator/IS.SHP.GOOD.T $\mathrm{U}$

17. Gamassa Pascal Kany Prud'ome and Chen Yan, "Application of Several Models for the Forecasting of the container Throughput of the Abidjan port in Ivory Coast", International Journal of Engineering Research in Africa, vol. 28, pp. 157-168, (2017)

18. http://www.doingbusiness.org/data/exploreeconomie s/burkina-faso

19. Carana corporation, "Impact of transport and logistics on Mali's trade competitiveness", United States Agency for International Development, pp. 184, (2004)

20. African development report, "Connecting Ports to the Markets", AfricanBank, pp. 107- 153, (2010)

21. https://www.distancecalculator.net/from-bamako-toabidjan

22. Borderless, "Abidjan-Ouagadougou Corridor Road Governance Report", West African Economic and Monetary Union, pp. 1-17, (2013)

23. http://www.railwaygazette.com/news/infrastructure/s ingle-view/view/abidjan-ouagadougou-railwayupgrade-begins.html

24. http://foreignpolicy.com/2017/01/12/the-real-cost-ofivory-coasts-military-mutiny-africa-fastest-growingeconomy/

25. Regine Adele Ngono Fouda, Nana Darcis Romeo, Muhammad Azizi, S. Rick Fernandez, "Port Logistics in West and Central Africa: A Strategic Development under Globalization", Open Journal of Applied Sciences, Vol. 4, pp. 76-84, (2014)

26. http://old.wordtravels.com/Travelguide/Countries/Iv ory+Coast/Map 